\title{
Development and Validation of a Filipino Eating Behavior Questionnaire among Adult Type 2 Diabetes Mellitus Patients
}

\author{
Anthony Harvey Aguilar, Mark Anthony Sandoval, Cecilia Jimeno, Elizabeth Paz-Pacheco \\ Section of Endocrinology, Diabetes and Metabolism, Department of Medicine, University of the Philippines - Philippine General Hospital Manila
}

\begin{abstract}
Background. Management of type 2 diabetes mellitus requires the maintenance of self-care behaviors, which include proper nutrition. However, diabetic patients often find that following a healthy diet is the most difficult component of self-care. It is important to assess the eating behaviors of diabetic individuals in order to customize a dietary plan but locally clinicians are hampered by the lack of a culturally adapted or validated tool.

Objective. The goal of this study is to develop and validate a Filipino eating behavior questionnaire for adults with type 2 diabetes mellitus.

Methodology. Literature review, expert interviews and focus group discussions among type 2 diabetic patients were done. All inputs, including pooled items from existing eating behavior questionnaires, were reviewed and categorized into corresponding eating behavior domains as determined by expert panel consensus. After translation into Filipino and pre-testing, the questionnaire was administered twice to 197 adults with type 2 diabetes. Questionnaire reliability was determined using Cronbach's $\alpha$ and Spearman's rank correlation coefficient.

Results. A 29-item, self-administered, Filipino eating behavior questionnaire answerable by a 4-point Likert scale was initially developed. This questionnaire featured three known eating behaviors namely: uncontrolled, restrained, and emotional eating; and included two newly identified eating behaviors: social and pro-active eating. In both first and second tests, only the items in the uncontrolled (Cronbach's a $0.739 \& 0.816$ ), social (Cronbach's $\alpha 0.641 \& 0.707$ ), and pro-active (Cronbach's a $0.622 \& 0.665$ ), eating domains were found to be internally consistent. One item under the restrained eating domain was deleted to improve the consistency of the items. For the test-retest reliability, moderate to high positive correlation (coefficients ranging from 0.530 to 0.744 ) between scale scores in the two test runs was achieved. This indicated stable responses to the items.
\end{abstract}

Conclusion. An eating behavior questionnaire for type 2 diabetic individuals that was developed to be culturally appropriate is a generally reliable, reproducible and valid instrument to assess eating behaviors. This study identified social and pro-active eating as behaviors among Filipinos with type 2 diabetes mellitus that were not previously described in foreign literature. The instrument may provide benefit in evaluating eating behaviors and formulating more individualized nutrition management plans.

Keywords: diabetes, eating, behavior, questionnaire, Filipino

\section{INTRODUCTION}

In the Philippines, approximately $7.2 \%$ of the population is diagnosed to have diabetes and its prevalence continues to increase as the prevalence of obesity escalates. ${ }^{1}$ Management of type 2 diabetes mellitus requires the adoption and maintenance of self-care behaviors, which include nutrition, aimed at achieving optimal metabolic outcomes and prevention of medical complications. ${ }^{2,3}$ Physicians often advise diabetic patients to adopt a healthy balanced diet and modify eating habits and patterns. ${ }^{4}$ However, diabetic patients find adherence to a healthy diet as most difficult component of self-care., ${ }^{5,6}$ Consequently, they fail to meet current treatment goals for glycemic control. ${ }^{7,8}$

e-ISSN 2308-118X

Printed in the Philippines

Copyright $@ 2014$ by the JAFES

Received June 24, 2014. Accepted July 15, 2014.

http://dx.doi.org/10.15605/jafes.029.02.10
The overall act of eating not only includes food intake per se, but also eating behavior in relation to preference, selection and consumption of food. ${ }^{4}$ Aside from behavior, it is also influenced by psychosocial and environmental factors. $^{5-6,11}$ Savoca et al., in 2001 reported that eating patterns were influenced by participants' knowledge of diabetes management, dietary self-efficacy, social support and time management. ${ }^{5}$ A similar study from the same authors in 2004 identified food habits like limiting portions and high-sugar foods, meal planning, and carbohydrate/vegetable strategies were all related to lower HbA1c levels. ${ }^{7}$

In the Treatment Options for type 2 Diabetes in Adolescents and Youth (TODAY) study, young patients

Corresponding author: Anthony Harvey I. Aguilar, MD

Section of Endocrinology, Diabetes and Metabolism

University of the Philippines-Philippine General Hospital

Taft Avenue, Ermita

1000 Manila, Philippines

Tel. No.: +632-554-8400 local 3230

E-mail: harvey.aguilarmd@gmail.com 
with type 2 diabetes who showed clinical (6\%) and subclinical $(20 \%)$ levels of binge eating were found to have higher rates of extreme obesity, global eating disorder, depressive symptoms and impaired quality of life. ${ }^{9}$ Moreover, a study by Mannucci et al., found that type 2 diabetes mellitus is unlikely to induce eating disturbances among obese patients. ${ }^{10}$ The study further supports the theory that external factors that influence eating behaviors play a significant role in the development of uncontrolled and emotional eating. Studies on eating behaviors among adults with type 2 diabetes are limited and no similar published studies were found in the Philippines.

The identification and understanding of eating behaviors and its relation to nutrition management could benefit both patients and physicians. Dietary restraint, loss of control over food intake and overeating during emotional distress have been identified as common eating behaviors, especially among obese subjects in foreign studies. ${ }^{12-15}$ Hence, several questionnaires such as the Restraint scale, Dutch eating behavior questionnaire, and Three-factor eating questionnaire have been developed and validated among obese and non-obese individuals. ${ }^{11,15-23}$

Research to better understand eating behaviors will help improve lifestyle education by identifying weaknesses in dietary practices. It may fill in the gap between knowledge on appropriate nutrition for patients with type 2 diabetes mellitus. ${ }^{4}$ The aim of every physician is to come up with nutrition education strategies that are individually tailored. To do this, we first need to be familiar with the general picture of eating behaviors in our local setting, hence, the goal of this study is to develop and validate a Filipino eating behavior questionnaire among adults with type 2 diabetes mellitus.

\section{METHODOLOGY}

\section{Phase 1: Literature review}

Based on the literature review, items from three eating behavior questionnaires (Three-factor eating behavior, Dutch eating behavior, and Restraint scale) were pooled to serve as reference for the construct of the new Filipino eating behavior questionnaire.

\section{Phase 2: Development of the conceptual framework and domains}

Upon approval of the University of the Philippines Manila Research Ethics Board, focus group discussions and expert consultations were carried out to identify eating behaviors among Filipinos that have not been previously described in the available literature.

Participants were patients with type 2 diabetes from the University of the Philippines - Philippine General

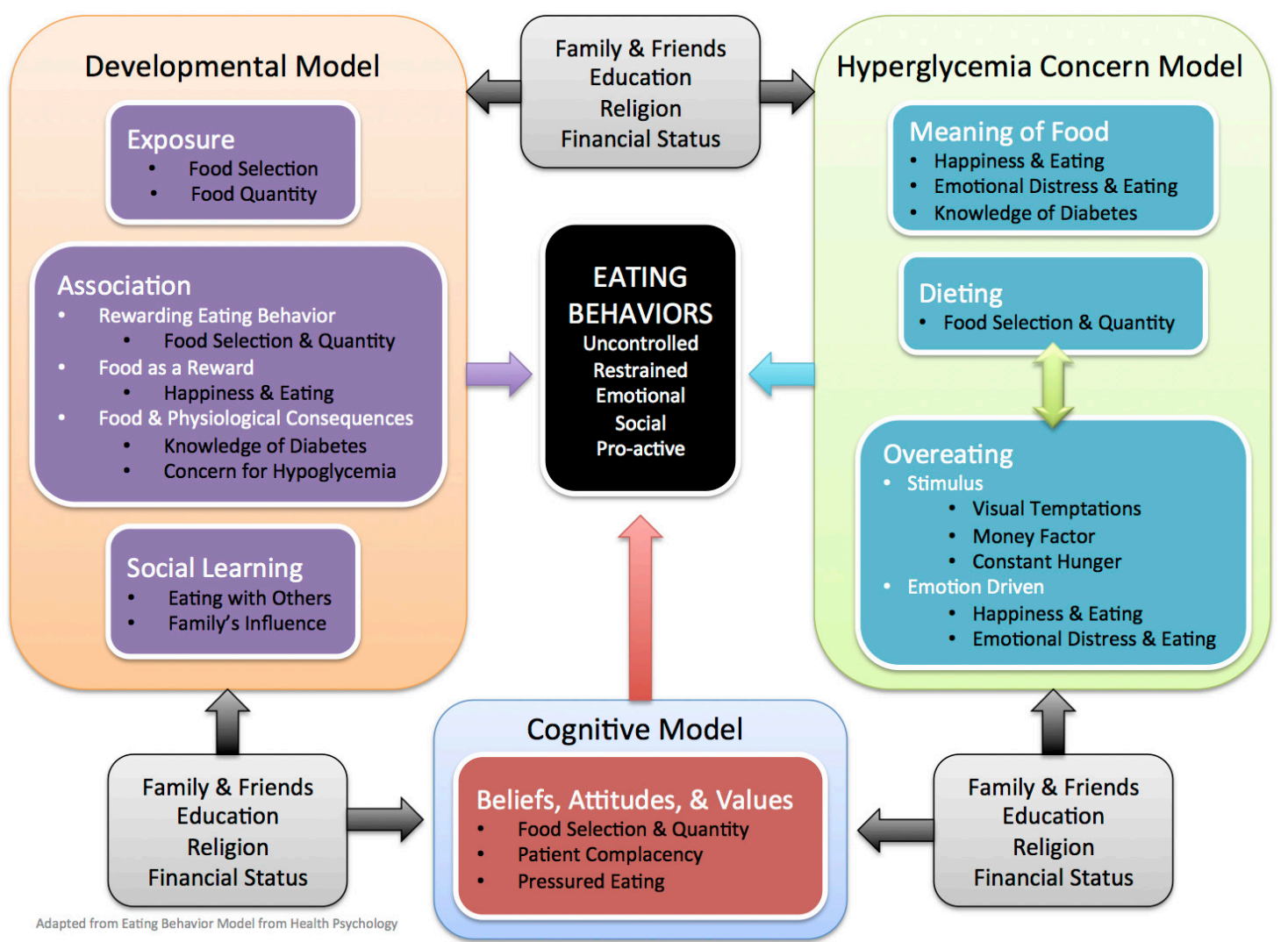

This adapted conceptual framework attempts to explain how concepts interlink and contribute to the development of an eating behavior. The developmental, cognitive, and hyperglycemia concern models demonstrate the presumed relationships among varying factors and influences.

Figure 1. The conceptual framework 
Hospital (UP-PGH) out-patient clinics who were recommended by their physicians and agreed to engage in the discussions. They were then divided into 5 groups, namely: group 1 - male, above 40 years $(n=6)$; group 2 female, above 40 years $(n=6)$; group 3 - male, 40 years and below $(n=4)$; group 4 - female, 40 years and below $(n=7)$; and group 5 - non-diabetic dieticians $(n=3)$ from the UPPGH dietary department who shared their encounters with type 2 diabetic patients during counselling sessions. The discussions included 24-hour food recalls, sharing of daily eating habits, and eating practices during special occasions and times of emotional distress. A voice recording was taken of every session to accurately document participants' responses, reactions, and even intonations.

Expert consultations were also done with an endocrinologist, nutritionist, psychiatrist and medical anthropologist. Most experts cited that Filipinos are fond of eating together as a family; that this sociocultural behavior results in loss of restraint or uncontrolled over eating; and diabetic patients are under social pressure to impress their hosts with abundance whenever food is offered.

After transcription, the participants responses were reviewed and categorized by the primary investigator and expert panel. Responses that were found to be similar to items from known eating behaviors were assigned to their respective domains. Initially uncategorized responses were reassessed and classified to form the eating behaviors newly identified among Filipinos with type 2 diabetes mellitus.

All participant responses were used to construct the conceptual framework and hybrid questionnaire, which was a combination of adapted items from established instruments plus the newly constructed items that were not covered by existing questionnaires.

\section{Phase 3: Translation and Back-translation}

The items of the hybrid questionnaire were translated from English to Filipino by two bilingual translators whose first language is Filipino. The first translator was a medical professional involved in the study while the second translator was a non-medical professional who was unaware of the concepts of the questionnaire. These two forward translations were reviewed and synthesized into a hybrid Filipino version. The hybrid version was then translated back to English by two other bilingual translators who did not have medical backgrounds. Linguistic and cultural quality of the questionnaire were reviewed. The panel consolidated all items and reached a consensus to produce a 29-item Filipino version that was culturally appropriate and conceptually equivalent to the originally constructed questionnaire. The questionnaire was answerable by a 4-point Likert scale with the following responses: almost always, frequently, seldom, and almost never.

\section{Phase 4: Pre-testing}

The pre-testing of the questionnaire was done among 20 type 2 diabetic patients at the UP-PGH out-patient clinics.

Majority of the respondents were elementary undergraduates. Twelve of them did not use insulin. The average time needed to finish answering the Filipino eating behavior questionnaire was 12 minutes. Words like "blood sugar" and "stress" were maintained and not translated to Filipino because these were commonly used by the respondents. An item to identify which respondents did not use insulin was added to guide the interpretation of the pro-active eating domain among insulin naive patients since most have not experienced hypoglycemia.

\section{Phase 5: Reliability Testing}

A total of 197 patients were recruited as questionnaire respondents. The study included patients who were 30-65 years of age; able to read, write and understand the Filipino language; diagnosed with type 2 diabetes based on the American Diabetes Association 2013 criteria; with disease duration of at least 6 months; and voluntarily joined the study after signing the informed consent form. All were referred by their physicians from the out-patient clinics of the UP-PGH through convenience sampling. Excluded from this study were patients diagnosed to have type 1 diabetes mellitus, women who were pregnant, and those on drugs which increase blood sugar levels such as steroids, anti-convulsants, atypical anti-psychotics, antifungals, sex hormones, anti-retrovirals, octreotide, lamivudine, and levothyroxine.

The internal consistency of the questionnaire was determined using Cronbach's $\alpha$. A minimal correlation of 0.60 was set to claim that the instrument and its subscale scores were acceptable. ${ }^{31}$ Spearman's rank correlation was used to correlate pairs of scores from the same participants given the same questionnaire at least one week apart. All analyses were conducted using the statistical program package Stata 12.

\section{RESULTS}

As shown in table 2, more than half of the respondents were females $(61 \%)$, married $(68.02 \%)$, able to attend or graduate from college $(62.44 \%)$, and were either retired or unemployed (65.48\%). The average age was $54.12 \pm 9.14$ years with diabetes duration of $9.53 \pm 7.91$ years. Around $37 \%$ were on insulin therapy. 
Table 1. Filipino eating behaviors of patients with type 2 diabetes and their definitions

1. Uncontrolled Eating It refers to the tendency to eat more than usual due to a loss of control over intake accompanied by subjective feelings of hunger. ${ }^{12}$

2. Restrained Eating is defined as the restriction of food intake in order to control or lower blood sugar levels.

3. Emotional Eating

It points to the inability of a patient to resist emotional cues. ${ }^{12}$

4. Social Eating

It is defined as increased eating in the company of familiar others.

It is enhanced eating in order to avoid the

5. Pro-active Eating signs and symptoms of hypoglycemia.

The first three eating behaviors were known from previous studies and also noted among Filipino patients with type 2 diabetes. The two eating behaviors newly identified in this group were named social and proactive eating.

\section{Internal Consistency}

In both first and second testings, only the items in the uncontrolled (Cronbach's $\alpha 0.739 \& 0.816)$, social $(\alpha 0.641$ $\& 0.707)$, and pro-active ( $\alpha 0.622 \& 0.665)$, eating domains were found to be internally consistent.

For the restrained eating domain, deletion of item 11 (It's hard for me to choose the right food whenever I eat in canteens or fast foods) could be done to reach the minimum acceptable value of 0.60 and raise the Cronbach's $\alpha$ from 0.586 and 0.608 to 0.679 and 0.705 for the first and second testings, respectively. The lowered Cronbach's $\alpha$ in this domain might be explained by item 11's statement about being in a
Table 2. Demographic \& clinical characteristics of the questionnaire respondents $(\mathrm{N}=197)$

\begin{tabular}{|c|c|}
\hline Average Age in years & $54.12 \pm 9.14$ \\
\hline \multicolumn{2}{|l|}{ Sex } \\
\hline Female & $120(61 \%)$ \\
\hline \multicolumn{2}{|l|}{ Marital Status } \\
\hline Single & $22(11.17 \%)$ \\
\hline Separated / Widowed & $32(16.24 \%)$ \\
\hline Married & $134(68.02 \%)$ \\
\hline With Live-in Partner & $9(4.57 \%)$ \\
\hline \multicolumn{2}{|l|}{ Educational Attainment } \\
\hline Elementary graduate or less & $20(10.15 \%)$ \\
\hline High school graduate or less & $54(27.41 \%)$ \\
\hline Some college / vocational course & $49(24.87 \%)$ \\
\hline College graduate & $74(37.56 \%)$ \\
\hline \multicolumn{2}{|l|}{ Employment } \\
\hline With full- / part-time work & $50(25.38 \%)$ \\
\hline With own business & $18(9.14 \%)$ \\
\hline Homemaker / retired / unemployed & $129(65.48 \%)$ \\
\hline \multicolumn{2}{|l|}{ Monthly Household Income } \\
\hline More than or equal to $P 10,000 /$ month & $100(50.76 \%)$ \\
\hline Less than $P 10,000 /$ month & $97(49.23 \%)$ \\
\hline \multicolumn{2}{|l|}{ Family History of Diabetes Mellitus } \\
\hline Yes & $141(71.57 \%)$ \\
\hline \multicolumn{2}{|l|}{ Medication Status } \\
\hline Diet \& exercise only & $10(5.08 \%)$ \\
\hline Oral hypoglycemic medications only & $113(57.36 \%)$ \\
\hline Insulin only & $12(6.09 \%)$ \\
\hline Combination of oral hypoglycemics \& insulin & $62(31.47 \%)$ \\
\hline Duration of Diabetes Mellitus in years & $9.53 \pm 7.91$ \\
\hline
\end{tabular}

situation where difficult food choices are made as opposed to the other items which all describe actions to control blood sugar.

Table 3. Internal consistency values of the Filipino eating behavior questionnaire - English version grouped according to domains $(\mathrm{N}=197)$

\begin{tabular}{|c|c|c|}
\hline Eating Behavior & $\begin{array}{c}\text { Cronbach's a } \\
\left(1^{\text {st }} \text { test }\right) \\
\text { if item deleted }\end{array}$ & $\begin{array}{c}\text { Cronbach's } \alpha \\
\text { (Retest) } \\
\text { if item deleted }\end{array}$ \\
\hline Uncontrolled Eating (UE) & 0.739 & 0.816 \\
\hline 1. I want to eat right away whenever I see the food I like. & 0.702 & 0.798 \\
\hline 3. I feel hungry because what I am eating is not enough. & 0.720 & 0.814 \\
\hline 8. It's hard for me to comply with my diet during parties. & 0.710 & 0.786 \\
\hline 13. If I have money, I buy and eat more food. & 0.698 & 0.798 \\
\hline 16. I become conscious of my diet only when I feel something bad. & 0.753 & 0.798 \\
\hline 18. I feel the urge to eat at any given time. & 0.713 & 0.786 \\
\hline 21. I can't help myself but eat a lot when the food I like is being served. & 0.711 & 0.789 \\
\hline 23. I eat the food gifts given by family and friends. & 0.726 & 0.806 \\
\hline 25. When I know that my blood sugar is controlled, I don't follow my prescribed diet. & 0.706 & 0.798 \\
\hline Restrained Eating (RE) & 0.586 & 0.608 \\
\hline 2. I avoid sweets because they have high sugar content. & 0.526 & 0.532 \\
\hline 4. I don't take second servings, even in parties, because my blood sugars will go up. & 0.529 & 0.530 \\
\hline 9. I lessen rice because it has high sugar content. & 0.478 & 0.538 \\
\hline 11. It's hard for me to choose the right food whenever I eat in canteens or fast foods. & 0.679 & 0.705 \\
\hline 14. I take small frequent meals in order to control my blood sugar. & 0.598 & 0.567 \\
\hline 17. I eat small portions in order to control my blood sugar. & 0.465 & 0.510 \\
\hline 26. I skip meals when I know that my blood sugar is high. & 0.585 & 0.639 \\
\hline 29. I am conscious of my diet because I have diabetes. & 0.501 & 0.527 \\
\hline Emotional Eating (EE) & 0.364 & 0.469 \\
\hline 5. When I feel stressed, I tend to overeat. & 0.208 & 0.280 \\
\hline 19. Whenever I feel happy, I eat the food I like even though it will raise my blood sugar. & 0.197 & 0.391 \\
\hline 22. When I feel stressed, I lose my appetite and eat less. & 0.644 & 0.627 \\
\hline 27. I find eating as a stress reliever so I eat more when I have problems. & 0.041 & 0.238 \\
\hline Social Eating (SE) & 0.641 & 0.707 \\
\hline 7. I lose control of my appetite whenever I eat with my family and friends. & 0.573 & 0.603 \\
\hline 10. I need to finish everything in my plate so that no food is wasted. & 0.595 & 0.641 \\
\hline 12. I can't refuse food offered to me because it might be regarded as an impolite act. & 0.616 & 0.704 \\
\hline 15. I tend to eat more when I dine with family and friends. & 0.494 & 0.590 \\
\hline 20. I follow my family's advice in adhering to a proper diet. & 0.647 & 0.731 \\
\hline Pro-active Eating (PE) & 0.622 & 0.665 \\
\hline 6. I don't want to feel the symptoms of having low blood sugar so I eat a lot. & 0.545 & 0.494 \\
\hline 24. I eat many times in a day because I am afraid of developing low blood sugar. & 0.420 & 0.599 \\
\hline 28. I immediately eat a lot whenever I feel dizzy, have cold sweats or tremors. & 0.593 & 0.610 \\
\hline
\end{tabular}




\begin{tabular}{|c|c|}
\hline Item & Correlation Coefficient \\
\hline 1. I want to eat right away whenever I see the food I like. & $0.510^{m+}$ \\
\hline 2. I avoid sweets because they have high sugar content. & $0.484^{\pi *}$ \\
\hline 3. I feel hungry because what I am eating is not enough. & $0.534^{\pi *}$ \\
\hline 4. I don't take second servings, even in parties, because my blood sugars will go up. & $0.254^{\pi *}$ \\
\hline 5. When I feel stressed, I tend to overeat. & 0.558 \\
\hline 6. I don't want to feel the symptoms of having low blood sugar so I eat a lot. & $0.538^{\pi x}$ \\
\hline 7. I lose control of my appetite whenever I eat with my family and friends. & $0.505^{x \pi}$ \\
\hline 8. It's hard for me to comply with my diet during parties. & $0.566^{\pi *}$ \\
\hline 9. I lessen rice because it has high sugar content. & 0.512 \\
\hline 10. I need to finish everything in my plate so that no food is wasted. & 0.524 \\
\hline 11. It's hard for me to choose the right food whenever I eat in canteens or fast foods. & $0.556^{\pi x}$ \\
\hline 12. I can't refuse food offered to me because it might be regarded as an impolite act. & $0.407^{\pi x}$ \\
\hline 13. If I have money, I buy and eat more food. & $0.614^{\pi *}$ \\
\hline 14. I take small frequent meals in order to control my blood sugar. & $0.537^{\prime \prime}$ \\
\hline 15. I tend to eat more when I dine with family and friends. & 0.616 \\
\hline 16. I become conscious of my diet only when I feel something bad. & $0.511^{\pi x}$ \\
\hline 17. I eat small portions in order to control my blood sugar. & $0.638^{\mathrm{x}}$ \\
\hline 18. I feel the urge to eat at any given time. & $0.586^{* *}$ \\
\hline 19. Whenever I feel happy, I eat the food I like even though it will raise my blood sugar. & 0.432 \\
\hline 20. I follow my family's advice in adhering to a proper diet. & 0.516 \\
\hline 21. I can't help myself but eat a lot when the food I like is being served. & $0.544^{\pi *}$ \\
\hline 22. When I feel stressed, I lose my appetite and eat less. & $0.445^{\pi *}$ \\
\hline 23. I eat food gifts given by family and friends. & $0.570^{\pi *}$ \\
\hline 24. I eat many times in a day because I am afraid of developing low blood sugar. & 0.568 \\
\hline 25. When I know that my blood sugar is controlled, I don't follow my prescribed diet. & $0.556^{\pi x}$ \\
\hline 26. I skip meals when I know that my blood sugar is high. & $0.440^{\mathrm{x}}$ \\
\hline 27. I find eating as a stress reliever so I eat more when I have problems. & $0.584^{\pi *}$ \\
\hline 28. I immediately eat a lot whenever I feel dizzy, have cold sweats or tremors. & $0.669^{\pi *}$ \\
\hline 29. I am conscious of my diet because I have diabetes. & $0.508^{\pi *}$ \\
\hline
\end{tabular}

On the other hand, item 22 (When I feel stressed, I lose my appetite and eat less) of the emotional eating domain could be deleted to increase the internal consistency from 0.364 and 0.469 to 0.644 and 0.627 for the first and second testings, respectively. This item differed from the rest since it pertains to loss of appetite related to emotional distress unlike the other items which showed emotiondriven overeating. However, the expert panel decided to retain this item because it covers an aspect of emotional eating that leads to undereating.

\section{Test-Retest Reliability}

A total of 163 out of 197 respondents were able take the second testing. The mean test-retest interval was 9 days $(\mathrm{SD}=4.36$ days). As shown in table 4, statistically significant ( $p$-value $<0.05$ ) moderate, positive correlation, ranging from 0.407 to 0.669 , indicated fairly stable responses in the two runs of the questionnaire. However, item 4 (I don't take second servings, even in parties, because my blood sugars will go up) demonstrated a relatively low correlation coefficient of 0.254. A possible explanation could be the use of negative Filipino words such as "hindi" (do not) at the beginning of the item. Answering this item with the choice "halos hindi" (almost never) could confuse the respondent in the two tests since the answer gave the statement in a "double negative" construction.

If the items were taken as a group by domains (Table 5), statistically significant ( $\mathrm{p}$-value $<0.05$ ) moderate to high positive correlation, ranging from 0.569 to 0.744 , between scale scores in the first and second runs were observed and indicated stable responses.
Table 5. Per domain correlation between scale scores in the test-retest $(\mathrm{N}=163)$

\begin{tabular}{cc}
\hline Domains & Correlation Coefficient \\
\hline Uncontrolled Eating & 0.744 \\
Restrained Eating & $0.626^{* *}$ \\
Emotional Eating & $0.569^{* *}$ \\
Social Eating & $0.681^{* *}$ \\
Pro-active Eating & $0.699^{* *}$ \\
${ }^{* *} \mathrm{p}$-value $=.000$ &
\end{tabular}

The final questionnaire is a 28-item, Filipino eating behavior questionnaire for adults with type 2 diabetes mellitus.

\section{DISCUSSION}

The questionnaire featured three known eating behavior domains which include uncontrolled, restrained and emotional eating plus two new domains that were named social and pro-active eating. The known eating behaviors were adapted from questionnaires for obese patients and these three behaviors were also observed in this population. This finding was somewhat expected since uncontrolled, restrained and emotional eating had been identified as common eating behaviors based on previous studies. $^{8-11}$ Furthermore, type 2 diabetic patients are usually overweight or obese patients, hence, the probability of similar eating behaviors.

Uncontrolled eating was a frequent topic during the expert consultations and patient discussions. Different situations like the presence of tempting foods, having extra money and knowing one has a controlled blood sugar could lead to complacency and loss of control over eating. Studies report the prevalence of binge eating disorders among 
type 2 diabetics to range from 2.5 to $25.6 \% .^{27-30}$ They support binge eating as a cause of increase in body weight and ultimately, a risk for type 2 diabetes mellitus development. ${ }^{4}$ Moreover, both binge eating and obesity may independently contribute to diabetes onset. ${ }^{28}$

Restrained eating was likewise identified in this study. Findings of Manucci et al., showed higher scores on the restraint scale among diabetic patients compared to obese non-diabetic controls. The explanation is that the diagnosis of diabetes intensified the drive for weight loss resulting in a more controlled diet. ${ }^{27}$ Similarly, participants of the group discussions expressed knowledge of having diabetes was a big factor in shifting to healthier food selections and portions.

For the emotional eating domain, happiness and distress were mostly described by this group. The four items under this domain illustrated two possible links of emotions to eating. Negative emotions, as exemplified by items 5 (When I feel stressed, I tend to overeat) and 27 (I find eating as a stress reliever so I eat more when I have problems), promote eating in order to regulate emotions. ${ }^{37}$ Some individuals use eating as a coping mechanism to alleviate negative moods and mask their stress. ${ }^{39-40}$ In addition, the processing of emotions requires attention and can lead to the loss of focus on the control of eating. ${ }^{37}$ Emotions can modulate eating in congruence with emotional features as well. ${ }^{37}$ Sadness or emotional distress was observed to decrease and happiness to increase food pleasantness and motivation to eat more. ${ }^{41}$ Based on discussions, patients associated happiness to celebrations and achievements that lead to the tendency to overeat and give in to prohibited foods, while some revealed that stress makes them lose their appetite. These behaviors were reflected in items 19 (Whenever I feel happy, I eat the food I like even though it will raise my blood sugar) and 22 (When I feel stressed, I lose my appetite and eat less).

The newly identified eating behavior termed "social eating" was defined as increased eating in the company of familiar persons. It was a prominent idea during the interviews and group discussions since Filipinos recognize the importance of eating as a social function. Accordingly, eating with family and friends can be enhanced by around $40-50 \%$ compared to eating alone. ${ }^{32-33}$ This is possibly explained by time extension, which states that when meals are eaten with others, meals tend to take longer, thereby increasing exposure to food cues and the opportunity to eat. $^{34}$ Another explanation for this behavior considers eating with others as a distraction that diverts attention away from finishing the meal and this causes the individual to eat more. ${ }^{35-36}$ Also, Filipinos with diabetes value the advice of loved ones about dieting (item 20) and the need to show courtesy to those who provided the food (items 10 and 12).
The other newly identified eating behavior is "pro-active eating." The three items (item 6, 24, and 28) under this domain refer to increased eating by patients with type 2 diabetes in order to avoid the signs and symptoms of hypoglycemia. The concern about hypoglycemia, particularly by insulin users, was identified as a possible factor that pushes patients to overeat because they fear experiencing hypoglycemia. Unlike uncontrolled eating, this behavior is distinguished by the presence of a motivation from a perceived danger. Studies show that hypoglycemia provokes loss of personal control, embarrassment and anxiety to the patient and the family members as well. ${ }^{37}$

Nutrition education is a key approach for effective diabetes management. ${ }^{5}$ The recognition of these eating behaviors, through the use of the Filipino eating behavior questionnaire, may assist in creating a focused and structured nutritional management plan. Uncontrolled eaters may benefit from behavioral approaches for food stimulus control and even appetite-suppression therapy; restrained eaters may be more receptive to complicated strategies such as calorie counting; emotional eaters may need support groups to address personal issues; social eaters may be offered ways on how to be more attentive to food intake when eating with others; and lastly, pro-active eaters may require a strictly scheduled diet to avoid hypoglycemia.

\section{CONCLUSION}

The study showed that a culturally appropriate eating behavior questionnaire for type 2 diabetic patients is a generally reliable, reproducible and valid instrument to assess eating behaviors. Aside from the known eating behaviors such as uncontrolled, restrained, and emotional eating, social and pro-active eating are newly described behaviors seen in this group of Filipinos with type 2 diabetes. The application of this questionnaire can potentially assist physicians and nutritionists in coming up with individualized nutrition plans. It might possibly be used in countries with a similar cultural milieu as the Philippines, where social eating is prevalent but at the same time there is great fear of hypoglycemia, hence, proactive eating is likewise observed.

\section{Acknowledgements}

My heartfelt gratitude goes to Dr. Mary Ann Ladia from the Department of Clinical Epidemiology, University of the Philippines-Manila; Dr. Belle Erika Nubla-Gestuvo \& Dr. Louie Rebuccal from the UP-PGH Department of Psychiatry; Ms. Elizabeth Limos from the UP-PGH Dietary department; Mr. Sumsabalip Alatiit, Ms. Renee Rose Cantos \& Mr. Leonard David Espiritu for the translations. Thank you also to the Philippine Society of Endocrinology, Diabetes \& Metabolism who provided funding for this research. 


\section{References}

1. Sy RG, Morales DD, Dans AL, et al. Prevalence of atherosclerosisrelated risk factors and diseases in the Philippines. J Epidemiol. 2012; 22(5): 440-447. http://dx.doi.org/10.2188/jea.JE20110095.

2. Diabetes Control and Complications Trial Research Group. The effect of intensive treatment of diabetes on the development and progression of long-term complications in insulin-dependent diabetes mellitus. N Eng J Med. 1993; 329: 977-1036. http://dx.doi.org/10.1056/NEJM199309303291401.

3. UK Prospective Diabetes Study Group. Intensive blood-glucose control with sulphonylureas or insulin compared with conventional treatment and risk of complications in patients with type 2 diabetes (33). Lancet 1998; 352: 837-53. http://dx.doi.org/10.1016/S01406736(98)07019-6.

4. Yannakoulia M. Eating behavior among type 2 diabetic patients: A poorly recognized aspect in a poorly controlled disease. Rev Diabetic Stud. 2006; 3: 11-16. http://dx.doi.org/10.1900/RDS.2006.3.11

5. Savoca M, Miller C. Food selection and eating patterns: Themes found among people with type 2 diabetes mellitus. J Nutri Educ. 2001; 33: 224-233. http://dx.doi.org/10.1016/S1499-4046(06)60035-3.

6. Sullivan ED, Joseph DH. Struggling with behavior changes: A special case for clients with diabetes. Diabetes Educ 1998; 24: 72-77. http://dx.doi.org/10.1177/014572179802400110.

7. Savoca M, Miller C, Ludwig D. Food habits are related to glycemic control among people with type 2 diabetes mellitus. J Am Diet Assoc. 2004; 104: 560-566. http://dx.doi.org/10.1016/j.jada.2004.01.013.

8. Harris MI. Racial and ethnic differences in health care access and health outcomes of adults with type 2 diabetes. Diabetes Care. 2001; 24: 454-459. http://dx.doi.org/10.2337/diacare.24.3.454.

9. Treatment options for type 2 diabetes in adolescents and youth (today) study group. A clinical trial to maintain glycemic control in youth with type 2 diabetes. N Engl J Med. 2012; 366: 2247-2256.

10. Nestle M, Wing R, Birch, et al. Behavioral and social influences on food choice. Nutr Rev. 1998; 56: S50-74

11. De Lauzon B, Romon M, Deschamps V, et al. The three-factor eating questionnaire-R18 is able to distinguish among different eating patterns in a general population. J Nutri. 2004; 2372-2380.

12. Tuschl RJ. From dietary restraint to binge eating: Some theoretical considerations. Appetite. 1990; 14: 105-109. http://dx.doi.org/10.1016/0195-6663(90)90004-R.

13. Blundell JE \& Gillett A. Control of food intake in the obese. Obese Res. 2001; 9 (Suppl. 4): 263S-270S.

14. Allison DB \& Heshka S. Emotion and eating in obesity? A critical analysis. Int J Eat Disord. 1993; 13: 289-295. http://dx.doi.org/ 10.1002/1098-108X(199304)13:3<289::AID-EAT2260130307>3.0.CO;2-X.

15. Stunkard AJ, Messick S. The three-factor eating questionnaire to measure dietary restraint, disinhibition and hunger. J Psychosom Res. 1985; 29: 71-83. http://dx.doi.org/10.1016/0022-3999(85)90010-8.

16. Karlsson J, Perssom L-O, Sjostrom L, et al. Psychometric properties and factor structure of the three-factor eating questionnaire (TFEQ) in obese men and women. results from the swedish obese subjects (SOS) study. Int J Obes. 2000; 24:1715-1725. http://dx.doi.org/10.1038/sj.ijo.0801442.

17. Angle S, Engblom J, Eriksson $\mathrm{T}$, et al. Three factor eating questionnaire-R18 as a measure of cognitive restraint, uncontrolled eating and emotional eating in a sample of young finnish females. Int J Behavi Nutri \& Phys Act. 2009; 6:41 (1-7)

18. Cappelleri JC, Bushmakin AG, Gerber RA, et.al. Psychometric analysis of the three-factor eating questionnaire-R21: results from a large diverse sample of obese and non-obese participants. Int J Obes. 2009; 33:611-620. http://dx.doi.org/10.1038/ijo.2009.74.

19. Heatherton TF, Herman CP, Polivy J, et.al. The (mis)measurement of restraint: An analysis of conceptual and psychometric issues. J Abnorm Psychol. 1988; 97:19-28. http://dx.doi.org/10.1037/0021843X.97.1.19.
20. Williamson DA, Martin CK, York-Crowe E, et al. Measurement of dietary restraint: Validity tests of four questionnaires. Appetite. 2007 48:183-192. http://dx.doi.org/10.1016/j.appet.2006.08.066.

21. Allison DB, Gorman BS, Kalinsky LB. A comparison of the psychometric properties of three measures of dietary restraint. Psychol Asses. 1992; 4:391-398. http://dx.doi.org/10.1037/10403590.4.3.391.

22. Laessle RG, Tuschl RJ, Kotthaus BC, Pirke KM. A comparison of the validity of three scales for the assessment of dietary restraint. J Abnorm Psychol. 1989; 4:504-507. http://dx.doi.org/10.1037/0021843X.98.4.504.

23. Chearskul S, Pummoung S, Vongsaiyat S, et.al. Thai version of threefactor eating questionnaire. Appetite. 2010; 54:410-413. http://dx.doi.org/10.1016/j.appet.2010.01.005.

24. Oltersdorf U, Schlettweing-Gsell D, Winkler G. Assessing eating patterns- an emerging research topic in nutritional sciences: Introduction to the symposium. Appetite. 1999; 32:1-7. http://dx.doi.org/10.1006/appe.1998.0189.

25. Ogden J. "Eating behaviour." Health Psychology, 5th ed. McGrawHill, 2012. 133-165.

26. Manucci E, Tesi F, Ricca F, et al. Eating behavior in obese patients with and without type 2 diabetes mellitus. Int J Obes Relat Metab Disord. 2002. 26(6):848-853.

27. Kenardy J, Mensch M, Bowen K, et al. Disordered eating behaviors in women with type 2 diabetes mellitus. Eat Behav. 2001. 2(2):183-192.

28. Herpetz S, Albus C, Wagener R, et al. Comorbidity of diabetes and eating disorders. Does diabetes control reflect disturbed eating behavior? Diabetes Care. 1998. 21(7):1110-1116.

29. Crow S, Kendall D, Praus B, Thuras P. Binge eating and other psychopathology in patients with type II diabetes mellitus. Int J Eat Disord. 2001. 30(2):222-226.

30. Abhaya, I. "Quality considerations." Medical Biostatistics, 2nd ed. Chapman \& Hall / CRC Biostatistics Series, 2008. 545-571.

31. De Castro JM. Family \& friends produce greater facilitation of food intake than other companions. Physiol Behav. 1994; 56:445-55. http://dx.doi.org/10.1016/0031-9384(94)90286-0.

32. Shide DJ, Rolls BJ. Social facilitation of caloric intake in humans by friends but not strangers. Int J Obes. 1991; 15:8.

33. De Castro JM. Social facilitation of duration \& size but not rate of the spontaneous meal intake of humans. Physiol Behav. 1990; 47:1129-35. http://dx.doi.org/10.1016/0031-9384(90)90363-9.

34. Bellisle F, Dalix AM. Cognitive restraint can be offset by distraction, leading to increased meal intake in women. Am J Clin Nutr. 2001 74:197-200.

35. Mitchell GI, Brunstrom JM. Everyday dietary behavior \& the relationship between attention \& meal size. Appetite. 2005; 45:344-45. http://dx.doi.org/10.1016/j.appet.2005.06.001

36. Frier BM. How hypoglycemia can affect the life of a person with diabetes. Diabetes Metab Res Rev. 2008; 24:87-92. http://dx.doi.org/10.1002/dmrr.796.

37. Macht M. How emotions affect eating: A five-way model. Appetite. 2007; 50:1-11. http://dx.doi.org/10.1016/j.appet.2007.07.002.

38. Marx RG, Menezes A, Horovitz L, et al. A comparison of two time intervals for test-retest reliability of health status instruments. J Clin Epidemiol. 2003; 56:730-735. http://dx.doi.org/10.1016/S08954356(03)00084-2

39. Thayer RE. Calm Energy - How people regulate mood with food and exercise. Oxford: Oxford University Press.

40. Polivy J \& Herman, CP. Distress and eating: Why dieters overeat? Int J of Eat Disord. 1999; 26: 153-164.

41. Macht M, Roth S, \& Ellgring $\mathrm{H}$. Chocolate eating in healthy men during experimentally induced sadness and joy. Appetite. 2002 39:147-158. http://dx.doi.org/10.1006/appe.2002.0499.

Articles and any other material published in the JAFES represent the work of the author(s) and should not be construed to reflect the opinions of the Editors or the Publisher. Authors are required to accomplish, sign and submit scanned copies of the JAFES Declaration: that the article represents original material, that is not being considered for publication or has not been published or accepted for publication elsewhere. Consent forms, as appropriate, have been secured for the publication of information about patients; otherwise, authors declared that all means have been exhausted for securing such consent. The authors have signed disclosures that there are no financial or other relationships that might lead to a conflict of interest. All authors are required to submit Authorship Certifications that the manuscript has been read and approved by all authors, and that the requirements for authorship have been met by each author. 


\section{APPENDIX}

\section{FILIPINO EATING BEHAVIOR QUESTIONNAIRE FOR ADULT TYPE 2 DIABETES MELLITUS PATIENTS (English Version)}

Name: Date:

Age/Sex: Injects insulin: $\square$ Yes $\square$ No

Read the following statements carefully and answer them with all honesty. There are no right or wrong answers.

\section{Choose one and put a check $(\checkmark)$ on the box $\square$ of your answer.}

Notice that answer number 4 (Almost always) pertains to an eating behavior that you usually do while answer number 1 (Almost never) refers to an eating behavior that you least do.

1. I want to eat right away whenever I see the food I like.
(4) Almost always
(3) Frequent
(2) Seldom
(1) Almost never

2. I avoid sweets because they have high sugar content.
(4) Almost always
(3) Frequent
(2) Seldom
(1) Almost never

3. I feel hungry because what I am eating is not enough.
$\square$ (4) Almost always
(3) Frequent
(2) Seldom
(1) Almost never

4. I don't take second servings, even in parties, because my blood sugars will go up.
$\square$ (4) Almost always
(3) Frequent
(2) Seldom
(1) Almost never

5. When I feel stressed, I tend to overeat.
(4) Almost always
(3) Frequent
(2) Seldom
(1) Almost never

6. I don't want to feel the symptoms of having low blood sugar so I eat a lot.
(4) Almost always
(3) Frequent
(2) Seldom
(1) Almost never

7. I lose control of my appetite whenever I eat with my family and friends.
$\square$ (4) Almost always
(3) Frequent
$\square$ (2) Seldom
$\square$ (1) Almost never

8. It's hard for me to comply with my diet during parties.
$\square$ (4) Almost always
(3) Frequent
$\square$ (2) Seldom
(1) Almost never

9. I lessen rice because it has high sugar content.
$\square$ (4) Almost always
(3) Frequent
(2) Seldom
(1) Almost never

10. I need to finish everything in my plate so that no food is wasted.
$\square$ (4) Almost always
(3) Frequent
(2) Seldom
(1) Almost never

11. I can't refuse food offered to me because it might be regarded as an impolite act.
(4) Almost always
(3) Frequent
(2) Seldom
(1) Almost never

12. If I have money, I buy and eat more food.
(4) Almost always
(3) Frequent
(2) Seldom
(1) Almost never 
13. I take small frequent meals in order to control my blood sugar.
$\square$ (4) Almost always
(3) Frequent
(2) Seldom
$\square$ (1) Almost never

14. I tend to eat more when I dine with family and friends.
$\square$ (4) Almost always
(3) Frequent
$\square$ (2) Seldom
(1) Almost never

15. I become conscious of my diet only when I feel ill.
$\square$ (4) Almost always
(3) Frequent
(2) Seldom
(1) Almost never

16. I eat small portions in order to control my blood sugar.
$\square$ (4) Almost always
(3) Frequent
$\square$ (2) Seldom
(1) Almost never

17. I feel the urge to eat at any given time.
$\square$ (4) Almost always
(3) Frequent
(2) Seldom
(1) Almost never

18. Whenever I feel happy, I eat the food I like even though it will raise my blood sugar.
$\square$ (4) Almost always
(3) Frequent
$\square$ (2) Seldom
(1) Almost never

19. I follow my family's advice in adhering to a proper diet.
$\square$ (4) Almost always
(3) Frequent
$\square$ (2) Seldom
(1) Almost never

20. I can't help myself but eat a lot when the food I like is being served.
(4) Almost always
(3) Frequent
$\square$ (2) Seldom
(1) Almost never

21. When I feel stressed, I lose my appetite and eat less.
$\square$ (4) Almost always
(3) Frequent
$\square$ (2) Seldom
(1) Almost never

22. I eat the food gifts given by family and friends.
$\square$ (4) Almost always
(3) Frequent
$\square$ (2) Seldom
(1) Almost never

23. I eat many times in a day because I am afraid of developing low blood sugar.
$\square$ (4) Almost always
(3) Frequent
$\square$ (2) Seldom
$\square$ (1) Almost never

24. When I know that my blood sugar is controlled, I don't follow my prescribed diet.
(4) Almost always
(3) Frequent
$\square$ (2) Seldom
(1) Almost never

25. I skip meals when I know that my blood sugar is high.
$\square$ (4) Almost always
(3) Frequent
$\square$ (2) Seldom
(1) Almost never

26. I find eating as a stress reliever so I eat more when I have problems.
$\square$ (4) Almost always
(3) Frequent
(2) Seldom
(1) Almost never

27. I immediately eat a lot whenever I feel dizzy, have cold sweats or tremors.
$\square$ (4) Almost always
(3) Frequent
$\square$ (2) Seldom
(1) Almost never

28. I am conscious of my diet because I have diabetes.
$\square$ (4) Almost always
(3) Frequent
$\square$ (2) Seldom
(1) Almost never

End. 